\title{
REPRESENTAÇÃO DE SOTAQUES E ORALIDADE NA TRADUÇÃO FRANCESA DE ESTIVE EM LISBOA E LEMBREI DE VOCE, DE LUIZ RUFFATO
}

\author{
THE REPRESENTATION OF ACCENTS AND ORALITY IN THE FRENCH \\ TRANSLATION OF ESTIVE EM LISBOA E LEMBREI DE VOCÊ BY LUIZ \\ RUFFATO
}

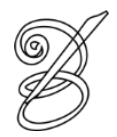 \\ Kall Lyws Barroso SALES ${ }^{1}$ \\ Universidade Federal de Santa Catarina \\ Ilana HEINEBERG ${ }^{2}$ \\ Université Bordeaux-Montaigne, França
}

\begin{abstract}
Resumo: A tradução das oralidades ficcionais é um assunto muito produtivo nos Estudos da Tradução, e muitos teóricos já abordaram o uso do registro oral na construção da prosa literária (BUCKLEY, 2000; BERMAN, 2012; VITALI, 2011). Dessa forma, o presente artigo tem o objetivo de analisar as estratégias tradutórias da representação de oralidades e de sotaques na prosa de Luiz Ruffato. Para tanto, escolhemos a tradução francesa de Mathieu Dosse, À Lisbonne j'ai pensé à toi, publicada em 2015 pela Editora Chandeigne, por se tratar de um romance que contém diversos registros do português brasileiro, além das variantes brasileira e portuguesa. Num primeiro momento, apresentamos sumariamente a escrita de Ruffato no cenário da literatura brasileira traduzida e o modo como sua prosa se mostra ao público francês. A seguir, levantamos a literatura crítica que versa sobre o registro oral e a representação dos sotaques no domínio escrito. Buscamos, enfim, dar visibilidade à tarefa do tradutor, considerando-a como uma leitura crítica e aprofundada do texto que será traduzido.
\end{abstract}

Palavras-chave: Tradução. Oralidade. Literatura brasileira. Luiz Ruffato.

Abstract: The translation of fictional orality is a very productive subject in Translation Studies, many theorists having already studied the use of orality in literature (BERMAN, 2012; VITALI, 2011). Thereby, the present article intends to analyze the strategies for translating the oral representations and accents present in Luiz Ruffato's novels. We have chosen, to that end, the French translation of Mathieu Dosse, À Lisbonne j'ai pensé à toi, published in 2015 by the Publishing House Chandeigne, because it is a novel that contains several variations of Portuguese spoken in Brazil and in Portugal. Firstly, we briefly contextualize Ruffato's writing within translated Brazilian literature, as well as the way his novel is presented to the French public. Next, we set forth the critical literature analyzing oral marks and the representation of accents in the novels. Finally, we seek to give visibility to the translator's task, considering it a critical and in-depth reading of the text to be translated.

Keywords: Translation. Orality. Brazilian Literature. Luiz Ruffato.

RECEBIDO EM: 12/12/2017

ACEITO EM: 17/04/2018

PUBLICADO EM: julho 2018

SALES; HEINEBERG. Representação de sotaques e oralidade na tradução francesa de Estive em Lisboa e lembrei de você, de Luiz Ruffato

Belas Infiéis, v. 7, n. 1, p. 39-58, 2018. 


\section{Luiz Ruffato: edições, traduções e mercado editorial}

utor de romances, contos, poemas e ensaios, o mineiro Luiz Ruffato, nascido em 1961, em Cataguases (Minas Gerais), tem fama reconhecida no cenário literário

brasileiro, e as traduções de seus livros para diversas línguas alavancaram o seu sucesso internacional. Ruffato tem reconhecido e prestigiado os seus tradutores. Em 2016, por exemplo, na cerimônia de entrega do prêmio literário Hermann Hesse, na Alemanha, o autor fez questão de dividir as honras com seu tradutor para o alemão, Michael Kegler, pois afirmou que o prêmio não seria só dele, já que é "resultado de um trabalho em conjunto com o Kegler, que tem um método de tradução minucioso, porque anota todas as dúvidas e discutimos sobre cada uma delas" (ROSA, 2016).

Algumas das traduções dos romances de Ruffato estão cadastradas no Index Translationum da Unesco, mas a lista de romances traduzidos apresenta apenas as traduções para o francês publicadas pela editora Métailié. Contudo, sua produção conta com outras traduções no mercado editorial de diversos países. Uma das primeiras traduções de Ruffato, por exemplo, foi o romance Eles eram muitos cavalos $^{3}$, que chegou à Itália em 2003, Come tanti 40 cavalli, tradução de Patrizia di Malta publicada pela Bevivino Editore. Ainda na Itália, Ruffato conta com, pelo menos, mais uma tradução: Sono stato a Lisbona e ho pensato a te, realizada por Gian Luigi de Rosa e lançada em 2011 pela Editora La Nuova Frontiera ${ }^{4}$.

Seus romances também têm versões em espanhol na América Latina5: na Argentina, por exemplo, dois de seus textos foram lançados pela Editora Eterna Cadencia e traduzidos por Mario Camara: Ellos eran muchos caballos, publicado em 2010, e Estuve en Lisboa y me acordé de ti, publicado em 2011. No México, Ruffato também conta com duas traduções, ambas lançadas pela editora Elephas e traduzidas por Maria Cristina Hernández Escobar: Mamma, son tanto Felice, publicada em 2011; e El mundo enemigo [O mundo inimigo], lançada em 2012. Ainda em 2012, a tradução Ellos eran muchos caballos, de Mario Camara, ganha uma edição colombiana publicada pela editora Rey + Naranjo.

Também acrescentamos à lista de traduções de seu romance Eles eram muitos cavalos o texto em alemão Es waren viele Pferde, de Michael Kegler, publicado pela editora Assoziation em 2012; e a tradução para o finlandês Rutosti hevosiai, realizada por Jyrki LappiSeppälä, publicada pela editora Into em 2014. Além das edições nas línguas citadas, os romances de Ruffato também tiveram edições portuguesas: Eles eram muitos cavalos, lançado pela editora Quadrante Edições em 2006, Estive em Lisboa e lembrei-me de ti, publicado pela

SALES; HEINEBERG. Representação de sotaques e oralidade na tradução francesa de Estive em Lisboa e lembrei de você, de Luiz Ruffato

Belas Infiéis, v. 7, n. 1, p. 39-58, 2018. 
Quetzal Edições em 2010 e, por último, De mim já nem se lembra, publicado pela editora Tinta da China em 2012.

Já na França, Ruffato teve seu primeiro romance traduzido em 2005 pela Métailié, Tant et tant de chevaux, que foi traduzido "du brésilien" por Jacques Thiériot. Trata-se de uma tradução assumida ${ }^{7}$ na capa e na quarta capa, na qual o nome do tradutor é apresentado logo abaixo do título da obra. Entretanto, na reedição, publicada em 2012, também pela Métailié, a tradução passa a ser assumida, unicamente, na quarta capa, apresentando o nome da tradutora Maryvonne Lapouge (RUFFATO, 2012). Essa informação entra em confronto com o nome do tradutor da folha de rosto da edição de 2012, que continua apresentando Jacques Thiériot como o tradutor. Podemos inferir se tratar de um erro da edição, pois, apesar de apresentar o nome de outra tradutora, o texto traduzido é exatamente o mesmo da edição de 2005.

Depois de seu primeiro romance, Ruffato lança a pentalogia Inferno provisório pela editora Record: Mamma, son tanto Felice (2005), O mundo inimigo (2005), Vista Parcial da Noite (2006), O livro das impossibilidades (2008) e Domingo sem Deus (2011). A editora Métailié publicou apenas traduções dos dois primeiros volumes da coleção: Des gens heureux (2007), e Le monde ennemi (2010). Estas edições também são traduções assumidas na quarta capa, pois indicam ao leitor que o romance foi "traduit du brésilien par Jacques Thiériot". Nessas traduções, a língua da qual se traduz é o "brasileiro" e foram realizadas com o apoio do Centre National du Livre.

A recepção de Ruffato na França ainda conta com uma resenha crítica e uma tradução publicadas no jornal Le Monde. Neste, temos uma parte do romance Mundo inimigo traduzida por Pierre Léglise-Costa ${ }^{8}$ em 2010. Já em 2015, o mesmo jornal apresenta uma resenha crítica escrita por Verónica Mortaigne sobre o livro Estive em Lisboa e lembrei de você e sobre a linguagem do romance através da tradução de Mathieu Dosse.

Em 2009, com essa escrita do português do Brasil que mistura elementos de oralidade, ou seja, marcas do sotaque de Minas Gerais, bem como elementos do português de Lisboa e do Cabo-Verde, o romance Estive em Lisboa e lembrei de você foi publicado na Coleção Amores Expressos da Companhia das Letras ${ }^{9}$. Já em 2010, o romance ganha um novo título na edição portuguesa da Quetzal: Estive em Lisboa e lembrei-me de ti. O leitor da edição de Quetzal terá acesso ao título da edição brasileira somente na folha em que se apresenta o expediente do romance, na qual temos a informação "título: Estive em Lisboa e lembrei-me de ti e título original: Estive em Lisboa e lembrei de você” (RUFFATO, 2010).

SALES; HEINEBERG. Representação de sotaques e oralidade na tradução francesa de Estive em Lisboa e lembrei de você, de Luiz, Ruffato

Belas Infiéis, v. 7, n. 1, p. 39-58, 2018. 
A edição portuguesa não se limita a modificar o título da obra, mas também inúmeros elementos tipográficos da edição brasileira. Por exemplo, as palavras que aparecem em negrito na edição brasileira de 2009, “disse, “Adeusinho”” (2009, p.41), serão substituídas por palavras sem marca tipográfica nenhuma na edição portuguesa, "disse, "Adeusinho"” (2010, p. 43), assim, não estarão marcadas com negrito como na primeira edição: "velhas agasalhadas em xailes pretos" (2010, p.39); "velhas agasalhadas em xailes pretos" (2010, p.42). Podemos entender, então, que a "tradução" portuguesa não marcou o estranhamento de algumas palavras por percebê-las de forma corriqueira e habitual, diferente do leitor brasileiro. Como veremos mais adiante, a própria versão portuguesa do romance acaba por neutralizar uma crítica póscolonial presente na narrativa de Ruffato.

A tradução francesa do romance Estive em Lisboa e lembrei de você, intitulada $\grave{A}$ Lisbonne j'ai pensé à toi é assumida a partir da quarta capa e da folha de rosto, que apresentam o nome do tradutor. Ela foi publicada em 2015 pelas Edições Chandeigne e, segundo o expediente da obra, teve o apoio do Ministério da Cultura do Brasil e da Fundação Biblioteca Nacional (RUFFATO, 2015). Na quarta capa da edição, temos um pequeno texto introdutório 42 para que o leitor se sinta convidado à leitura e, logo após, uma pequena apresentação do autor da obra, seguida da informação sobre a tradução: “Traduction du portugais (Brésil) de Mathieu Dosse". Na folha de rosto, temos a mesma informação sobre a tradução apresentada abaixo do título da obra, que ganha destaque pelo tamanho da letra, seguida pelo nome do autor, que é apresentado acima do título da obra.

Recentemente, foi publicada uma entrevista de Mathieu Dosse, concedida às pesquisadoras Andreia Guerini e Leomaris Aires, na revista Cadernos de Tradução (GUERINI; AIRES 2017), juntamente com Gian Luigi De Rosa e Michael Kegler, respectivamente, tradutores para o italiano e para o alemão da obra de Ruffato. As entrevistas traçam os desafios enfrentados pelos tradutores de Estive em Lisboa e lembrei de você e, principalmente, as modificações das passagens do texto em que o sotaque de Minas Gerais é apresentado. Todos os tradutores abordaram os desafios que enfrentaram na representação do sotaque e também dos estranhamentos de Serginho com o português de Portugal.

Por isso, para entendermos a importância da linguagem narrativa da obra, devemos compreender que Estive em Lisboa e lembrei de você narra em primeira pessoa a história de Sérgio de Sousa Sampaio, nascido em Cataguases, Minas Gerais, em 1969. Todavia, antes de apresentar a prosa de "Serginho", o romance tem como epígrafes duas passagens de autores

SALES; HEINEBERG. Representação de sotaques e oralidade na tradução francesa de Estive em Lisboa e lembrei de você, de Luiz Ruffato

Belas Infiéis, v. 7, n. 1, p. 39-58, 2018. 
portugueses. A primeira - Sem lembrar / De ti eu vivo / Em Lisboa / A Magnífica” -, extraída da canção "Lisboa, a magnífica" do grupo de rock Xutos e Pontapés, mostra a capital do antigo império português como um lugar anônimo, um não-lugar (AUGÉ, 1992) aparentemente capaz de apagar a memória dos laços de origem. A segunda epígrafe, constituída pelo poema "Brasil”, do poeta Miguel Torga (1907-1995), aponta para a situação melancólica do eterno exílio vivido por aqueles que possuem uma dupla identidade, no caso do eu-lírico, portuguesa e brasileira.

A narrativa toma a forma de transcrição de um testemunho oral, já que Ruffato lança mão do artifício literário clássico do "autor transcritor" (TACCA, 1973, p. 34-64), fazendo-se passar por um simples copista ou pelo editor da obra que, na realidade, ele escreveu. É no espaço paratextual, essa zona de "transição, mas também de transação" (GENETTE, 2002, p. 8) entre texto e extra-texto, portanto entre ficção e real, que a estratégia narrativa de Ruffato se constrói. Ele utiliza uma "nota ficcional autoral denegativa" (GENETTE, 2002, p. 342), inserida antes do texto, para atestar a veracidade dos fatos contados. A narrativa de Serginho torna-se assim um "depoimento minimamente editado" e "gravado em quatro sessões nas tardes de sábados dos dias 9, 16, 23 e 30 de julho de 2015 na dependência do Solar dos Galegos" (RUFFATO, 2009, p. 13). Na mesma nota, o autor dedica o livro a Paulo Nogueira, "que o apresentou Serginho em Portugal”, e a Gilmar Santana, que “o conheceu no Brasil” (RUFFATO, 2009, p. 13). Dessa forma, a nota convida a um "pacto de leitura" (LEJEUNE, 1975) referencial que contradiz a classificação do livro como ficção, fazendo com que o leitor se questione constantemente sobre "a veracidade" do texto. No entanto, não se deve concluir que Ruffato, embora considerado pela crítica como um escritor "realista" (SCHØLLHAMMER, 2009, p. 7886), sirva-se do estratagema para reforçar a separação entre real e ficção. Pelo contrário, o autor mineiro tenta confundi-los, mostrando assim a capacidade do romance de dizer o real. Essa confusão aparece duplicada na própria narrativa, já que Serginho se projeta na migração de maneira totalmente ilusória, revelando também a presença de certa dose de ficção no seu mundo referencial. O título do livro evoca justamente o caráter quimérico de uma migração econômica, cujo retorno estaria garantido.

O romance é marcado por dois momentos: o primeiro diz respeito à vida de Serginho ainda em Cataguases, apresentado com o título Como parei de fumar (RUFATTO, 2009, p. 15) e o segundo, mais longo, Como voltei a fumar (Ibid., 2009, p. 39), em que o narrador conta sua experiência de migração a Lisboa. Cada momento da obra é importante para a empreitada tradutória, pois o romance se apresenta com uma infinidade de vozes e de marcas de oralidade

SALES; HEINEBERG. Representação de sotaques e oralidade na tradução francesa de Estive em Lisboa e lembrei de você, de Luiz, Ruffato

Belas Infiéis, v. 7, n. 1, p. 39-58, 2018. 
que faz com que o leitor, a todo instante, perceba diferentes registros, tipos de sotaque, de gírias e de manifestações do português.

$\mathrm{Na}$ primeira parte, o romance é permeado de palavras que geralmente não vemos escritas, por serem muito mais recorrentes em contextos orais. Os registros se apresentam de diversas formas no romance, pois, ao mesmo tempo em que temos "O quê que você vai fazer da vida agora, ô Serginho" (Ibid., 2009, p. 25), a palavra "você” é escrita sem nenhuma marca de variação na passagem: "vendo minha metade procê" (2009, p. 26), marcando um "procê" característico do falar de Minas Gerais. Essas nuances muitas vezes não se manifestam na tradução "je te vends ma moitié" (RUFFATO, 2015, p. 28). A sobreposição de registros presente na primeira parte dá cor local à língua portuguesa falada no Brasil e é perceptível, para o leitor brasileiro, a manifestação do sotaque mineiro na escrita dos diálogos.

Na segunda parte do romance, Como voltei a fumar, sobrepõem-se ao já marcado falar de Serginho as variantes do português de Portugal e de Cabo Verde, evidenciando uma performance de língua mutável, que se manifesta cheia de estranhamentos e particularidades. Nesse momento da narrativa, Serginho abandona a vida que não deu certo em Cataguases, com

44 o fracasso do casamento, o desemprego e a morte da mãe e parte para viver em Lisboa onde, supostamente, muito dinheiro aguarda aqueles que não têm medo de trabalhar duro, pois lá “dinheiro não é problema, falta é mão-de-obra” (RUFFATO, 2009, p. 26).

Ao chegar a Lisboa, Serginho estranha o vocabulário e a forma de falar dos portugueses a ponto de, ao encontrar com um compatriota, exclamar aliviado: "Puxa vida, que bom encontrar alguém que fala a mesma língua da gente!” (RUFFATO, 2009, p. 46). Entretanto, esse novo falar vai pouco a pouco integrando seu vocabulário, enriquecendo sua língua, resultando num falar "diglóssico", que permite a coabitação das duas variantes. O romance apresenta elementos da língua portuguesa que marcam a variante de Lisboa, a variante brasileira e, em particular, a variante de Minas Gerais, que são essenciais para a construção da narrativa de Estive em Lisboa e lembrei de você. Por isso, é importante percebermos como essa oralidade será representada também na tradução, pois as nuances entre um falar regional e um falar entendido como norma "padrão" podem mascarar a dominação de uma variante em detrimento de outras. Então, partimos agora para uma pequena análise das marcas de oralidade presentes na prosa de uma forma geral para, a seguir, analisarmos as soluções encontradas pelo tradutor francês.

$\overline{\text { SALES; HEINEBERG. Representação de sotaques e oralidade na tradução francesa de Estive em Lisboa e }}$ lembrei de você, de Luiz Ruffato

Belas Infiéis, v. 7, n. 1, p. 39-58, 2018. 


\section{A tradução das marcas de oralidade no texto literário}

Podemos dizer que a distinção entre a "língua falada" e a "língua escrita" da literatura, ou seja, aquilo que deve ser escrito e aquilo que deve ser apenas dito, é uma questão que remonta às origens das primeiras obras literárias escritas, e são uma constante nas literaturas de vários períodos, principalmente a partir do século XX (BERMAN, 2012, p. 82). O uso do registro oral tem uma razão de ser dentro da prosa e muitos recursos entram em jogo no momento em que se traduz uma marca de oralidade dentro do texto literário, pois a produção escrita, ao simular uma grafia das oralidades, pode evidenciar, por exemplo, o distanciamento que existe entre uma pronúncia marginalizada e uma pronúncia entendida como a norma linguística (BUCKLEY, 2000, p. 266). Por isso, a tradução de sotaques, para a além da sua representação no texto escrito, exige do tradutor uma reflexão sobre oralidades e sobre a realização dessas oralidades em um território que entendemos não ser o seu: o texto escrito.

No texto Algumas considerações sobre variação linguística e tradução literária, de Paganine e Fonseca (2015), temos reflexões sobre a representação literária das variações linguísticas em traduções, considerando que a discussão entre as variações de uma língua presente no texto deve preceder o ato tradutório. Partindo da ideia de que a uniformidade da língua é um mito, as autoras defendem o argumento de que as variações, sejam elas diatópicas ou diastráticas, estão presentes em praticamente toda obra literária em prosa. Aquilo que é conceituado erroneamente como variedade "subpadrão" costuma se apresentar menos na escrita formal e controlada. Mas, uma vez que essas variações estão presentes no texto literário, fica difícil separar o que é diatópico do que é diastrático, pois os traços regionais se "manifestam com mais nitidez na fala" das personagens e essa fala "permite o uso das variedades não padrão" (PAGANINE; FONSECA, 2015, p. 69). Ainda que apresente essas variedades não padrão, o “escrito literário pressupõe uma elaboração escrita do oral, mesmo quando sua intenção seja a de aproximar o que escreve da naturalidade da fala" (PRETI, 1999, p. 218). Por isso, podemos afirmar que a língua na literatura nunca perdeu sua ligação com a língua falada, pois escritores costumam aproximar a fala de suas personagens às manifestações de oralidade (PAGANINE; FONSECA, 2015, p. 71).

Os desafios que tanto escritores quanto tradutores enfrentam no momento da representação das oralidades são numerosos e um dos primeiros é a separação entre língua falada, "mais aberta às mudanças", e a língua escrita, "de caráter mais conservador" (PAGANINE; FONSECA, 2015, p. 71). Outra constante nas obras literárias é a apresentação

SALES; HEINEBERG. Representação de sotaques e oralidade na tradução francesa de Estive em Lisboa e lembrei de você, de Luiz Ruffato

Belas Infiéis, v. 7, n. 1, p. 39-58, 2018. 
de uma pronúncia, ou de um sotaque, que se faz presente em uma grafia não fixa, pois não podemos falar de transcrição fonética, já que geralmente os autores e tradutores estão livres para representar as pronúncias, no nível da escrita, sem se preocupar, por exemplo, com as normas do AFI (Alfabeto fonético internacional).

Mesmo assim, na tradução, geralmente existe uma separação entre aquilo que pode ser traduzido e aquilo que não pode ser traduzido. Essa separação geralmente está atrelada à ideia da universalidade linguística, que considera como universal uma variação de prestígio. Dialetos, gírias, palavrões e sotaques, exclusivamente associados à manifestação oral, quando são apresentados nas obras literárias - ou seja, numa realidade escrita - causam estranhamento. Por isso, personagens que têm um falar marcado com o "registro predominantemente oral" permanecem problemáticos na tradução. Podemos afirmar que as traduções tendem a um conservadorismo linguístico em relação às obras originais, já que, a partir do momento em que uma literatura apresenta elementos que outrora estavam resguardados à tradição oral, ela perturba a língua de partida e a língua para a qual se traduz, pois são textos que "se aventuram perigosamente" sobre o terreno do oral, dos dialetos, ou das escritas fonéticas artesanais 46 (BUCKLEY, 2000, p. 276).

Segundo Berman, a superposição das línguas na prosa tende a ser ameaçada na tradução. Para o teórico, é característica das obras literárias a presença de uma diversidade de vozes e traduzir essa multiplicidade “talvez seja o 'problema' mais agudo da tradução da prosa, pois toda prosa se caracteriza por superposições de línguas mais ou menos declaradas" (BERMAN, 2012, p. 87). Ao elaborar o conceito de letra, que pode ser entendido como a relação entre efeito e forma (BERMAN, 2012, p. 87), o teórico pretende apresentar a relação entre a existência material escrita da forma e do sentido. Em contrapartida, essa letra na tradução tradicional geralmente tende a ser mudada e padronizada a uma língua com menos variações, em favor de uma comunicabilidade do sentido, o que faz com que elementos essenciais e constitutivos estéticos e ideológicos da obra se manifestem de outra forma na tradução.

Ainda com relação à tradução da letra, podemos entender, então, que na tradução o importante seria traduzir aquilo que causa estranheza na obra literária por elementos que causem estranheza no leitor da tradução. Dessa forma, segundo os preceitos de A Tradução Literária, de Paulo Henriques Britto (2012, p. 67), podemos afirmar que devemos "traduzir o marcado pelo marcado e o não marcado pelo não marcado". Assim, nas passagens do texto de partida nas quais o leitor é confrontando com um recurso que seja destoante ou estranho, que

$\overline{\text { SALES; HEINEBERG. Representação de sotaques e oralidade na tradução francesa de Estive em Lisboa e }}$ lembrei de você, de Luiz Ruffato

Belas Infiéis, v. 7, n. 1, p. 39-58, 2018. 
aqui entendemos como "marcado", a tradução desse recurso também deverá ser "marcada", “destoante". São essas marcas de estranhamento que se apresentam na letra de Ruffato e são elas que analisamos na tradução de Estive em Lisboa e lembrei de você para o francês, com o objetivo de classificar as estratégias da tradução para a manutenção dos estranhamentos, dos sotaques e das diferenças vocabulares entre os diversos registros do português presentes no romance.

\title{
3. A tradução francesa das marcas de oralidade do romance Estive em Lisboa e lembrei de você
}

Como vimos, a tradução do romance Estive em Lisboa e lembrei de você é assumida a partir da quarta capa, pois nela encontramos uma pequena apresentação do autor brasileiro e também uma apresentação do tradutor, ao informar ao leitor de que o texto que está em suas mãos é uma "traduction du portugais (Brésil) de Mathieu Dosse". A tradução francesa apresenta uma paratradução produtiva ${ }^{10}$ que se inicia pela nota do tradutor, na qual ele explica sobre o estilo literário de Ruffato e sobre a proposta tradutória da presente edição:

\begin{abstract}
Serginho, o narrador, é um brasileiro de Minas Gerais. Na segunda parte da narrativa, seu português brasileiro, rico em expressões familiares, vai pouco a pouco integrando o vocabulário lisboeta. Essas novas palavras e expressões são marcadas, aqui e na edição original, em negrito. Como traduzir essa mudança sutil? Escolhemos deixar, já que nos parecia a melhor solução, a palavra em português seguida de uma tradução. Outras vezes, pareceu-nos necessário traduzir este efeito de estranheza, de deslocamento, que o "português de Portugal" geralmente produz aos ouvidos de um brasileiro. Assim, traduzimos algumas palavras ou expressões portuguesas por arcaísmos ("gouailler"), palavras incomuns em francês, um pouco antiquadas ("girie", "lieux d'aisance"), ou regionalismos ("cellulaire"). Raramente, enfim, traduzimos expressões ao pé da letra quando elas eram engraçadas ("chapeau à pluie" no lugar de "parapluie"). Sem dúvidas, fala-se, em Portugal e no Brasil, a mesma língua, mas as diferenças são tão grandes que Serginho chega a afirmar, num encontro com um compatriota em Lisboa: "Quand même, ça fait du bien de rencontrer quelqu'un qui parle la même langue que vous » [Puxa vida, que bom encontrar alguém que fala a mesma língua da gente (RUFFATO, 2009, p. 46)]. [Tradução nossa] ${ }^{11}$
\end{abstract}

Como o tradutor afirma em sua nota, a primeira estratégia, e a mais recorrente, para a tradução da variação do português de Portugal foi manter a palavra, tal qual apresentada no texto de Ruffato, grafada em negrito e seguida de um aposto explicativo em língua francesa: "des vieux avec des boinas, des bérets en laine" (RUFFATO, 2015, p.45) / "velhos de boinas de lã" (Idem, 2009, p. 39); “m 'a dit 'Adeusinho', au revoir" (2015, p. 47) / "disse, Adeusinho" (Idem, 2009, p. 41); “j’ai demandé le plat du jour, borrego assado, un rôti d'agneau”" (Idem,

SALES; HEINEBERG. Representação de sotaques e oralidade na tradução francesa de Estive em Lisboa e lembrei de você, de Luiz Ruffato

Belas Infiéis, v. 7, n. 1, p. 39-58, 2018. 
2015, p. 47) / "pedi um prato-do-dia, borrego assado" (2009, p. 44). Essa estratégia de seguir com uma frase explicativa aparece, de forma mais tímida, já no texto de Ruffato, quando, em alguns momentos, a narrativa precisa explicar para o leitor brasileiro algumas palavras do léxico português: "e sentei numa tasca, que é como eles chamam botequim" (Idem, 2009, p. 44). Contudo, nem sempre o leitor brasileiro tem acesso a todos os elementos, precisando, para compreender, buscar a informação em outras fontes ou conformar-se com o estranhamento. Essa estratégia tradutória dentro da narrativa é o que podemos compreender como clarificação, uma das tendências deformadoras apresentadas por Berman (2012, p. 70) e, por conseguinte, um alongamento (Ibidem, p. 71), já que, grosso modo, é uma tendência das traduções serem mais explicativas do que o texto de partida. Por exemplo, para o leitor do texto em português, talvez "borrego assado" não explicite imediatamente "carne de cordeiro", mas a estratégia da tradução evidencia, para o leitor do texto de chegada, através do aposto explicativo, o que significa "borrego assado", "un rôti d'agneau".

A segunda estratégia apontada pelo tradutor em sua nota foi a de traduzir o efeito de estranheza que o português de Portugal causa a um ouvinte brasileiro por palavras que causem 48 o mesmo efeito em leitores francófonos. Por isso, "quando o Serginho francês chega a Portugal, ele começa a usar palavras que soam diferentes para o leitor: regionalismos (como palavras usadas no Québec ou na Bélgica), arcaísmos, ou palavras e expressões um pouco raras, antigas, um pouco estranhas em francês" (GUERINI; AIRES, 2017, p. 410).

Os exemplos citados pelo autor foram: a tradução do verbo "troçar" na frase: "e os comensais troçaram" (RUFFATO, 2009, p. 50), que foi traduzida por "et ses commensaux ont gouaillé" (RUFFATO, 2015, p. 61); a frase "acho que nem ouviam mais as lamúrias" (Idem, 2009, p. 56) foi traduzida por “je crois qu'il n'entendait même plus ses giries" (Idem, 2015, p. 69); "lavava o chão e as casas de banho" (Idem, 2009, p. 56) foi traduzido por "nettoyait le sol et les lieux d'aisance" (2015, p. 69), e “o telemóvel desativado" (Idem, 2009, p.82) foi traduzido por "mon cellulaire coupê" (Idem, 2015, p. 105), que, segundo o tradutor, apresenta o regionalismo "cellulaire".

Todavia algumas palavras que causam estranhamento no leitor brasileiro foram traduzidas, muitas vezes, diretamente para o francês, como é o caso de "gajo", marcadamente um elemento do falar popular de Portugal. Por isso, quando a palavra aparece no romance, por exemplo, "é brasileiro, o gajo (2009, p. 50)", na tradução, a marca de estranhamento de "gajo" desaparece dando lugar a "lui" [ele], sem marca tipográfica: “C'est un brésilien, lui” (2015,

$\overline{\text { SALES; HEINEBERG. Representação de sotaques e oralidade na tradução francesa de Estive em Lisboa e }}$ lembrei de você, de Luiz Ruffato

Belas Infiéis, v. 7, n. 1, p. 39-58, 2018. 
p.61), embora "gajo" esteja marcadamente apresentado como elemento estranho graças ao uso do negrito no texto de partida. Entretanto, em outros momentos da tradução, a palavra "gajo" terá a marcação em negrito mantida, assim como outros elementos do português de Portugal, seguida, na primeira ocorrência, de um aposto explicativo: "plus tard, un autre gajo, un mec" (2015, p. 89). Nas ocorrências seguintes, se ela permanece no texto de chegada, é escrita e não é explicada, exigindo do leitor a memorização do elemento, pois o recurso do tradutor de apresentar um aposto explicativo só é usado na primeira vez em que a palavra aparece: "les clients préfèrent être servis par un gajo blond aux yeux bleus" (2015, p. 103).

Além dos exemplos apresentados pelo tradutor, houve a preocupação de evidenciar algumas sensações de estranhamento causadas no leitor brasileiro ao se deparar com algumas expressões de Portugal. Um dos exemplos é a utilização da expressão "pretos” para se referir às pessoas negras: "sobram oportunidades pros brasileiros e pros pretos (que é como eles chamam as pessoas de cor)" (RUFFATO, 2009, p. 26) traduzida por "Il reste de bonnes opportunités pour les Brésiliens et les Nègres (c'est comme ça qu'ils appellent les gens de couleur)" (2015, p. 27). Nessa primeira ocorrência, o narrador considera necessário explicar a conotação neutra da palavra em Portugal. Esse problema ainda permanece na tradução de "preto" por "nègre", palavra considerada pelos dicionários como injúria racial. Segundo Le Petit Robert (2017, p. 1681), "nègre”, e seu femino "négresse”, é arcaico, pejorativo, ou um "termo racista se não for empregado entre as próprias pessoas negras".

No Brasil, a palavra "preto" assume diversas categorias de representação e não é necessariamente ofensivo usar o termo "preto" ou "preta". Todavia, já o termo que se encontra entre parênteses "pessoas de cor" para explicar a palavra "preto" é muito mais problemático, tendo em vista que "pessoas de cor", assim como "pardo", "moreno", ou "mulato" são termos utilizados para o apagamento da negritude e que atualmente são combatidos nas mais diferentes esferas da sociedade brasileira, dentro e fora dos movimentos negros. Entretanto, entendemos que, para algum leitor brasileiro, a palavra "preto" pode assumir a característica de "termo sensível" e apresentar o sentido pejorativo e ofensivo, já que quem fala é um português branco. Por isso, na primeira vez que Serginho se depara com a palavra "preto", usada em Portugal, logo acrescenta uma explicação visando a sublinhar o cunho não pejorativo do uso na norma portuguesa. Dessa forma, quando a palavra "preto" aparece no texto, o tradutor opta por "nègre", de cunho injurioso e racista em francês, salvo se usado entre as pessoas negras. Como exemplos do texto temos as seguintes passagens: “colónias pros pretos” (RUFFATO, 2009, p.

SALES; HEINEBERG. Representação de sotaques e oralidade na tradução francesa de Estive em Lisboa e lembrei de você, de Luiz Ruffato

Belas Infiéis, v. 7, n. 1, p. 39-58, 2018. 
42) que foi traduzida por "colonies aux nègres" (RUFFATO, 2015, p. 49) e "que não escondia sua aversão por pretos" (Idem, 2009, p. 56) "qui ne cachait pas son aversion pour les nègres (Idem, 2015, p. 69).

A última estratégia elencada pelo tradutor em sua nota se refere ao fato de que algumas expressões em Portugal são cômicas para o leitor brasileiro e por isso, nestes casos, ele optou por traduzir "raramente" expressões "ao pé da letra". O exemplo vem com a tradução de "chapéu-de-chuva" (Idem, 2009, p. 46), a forma como os portugueses chamam guarda-chuva. Por conseguinte, ao invés de traduzir a palavra por "parapluie", opta por "chapeau-à-pluie" (Idem, 2015. p. 55) numa tentativa de manter o efeito cômico que a palavra causa para o leitor brasileiro.

Para além dos elementos indicados pelo tradutor em sua nota, também encontramos a representação de pronúncias na obra de Ruffato. Em seu texto, a manifestação de variantes do português - sotaque de Minas Gerais, de Lisboa e Cabo Verde. Por exemplo, na passagem em que o telefone toca, no Hotel do Vizeu, a personagem cabo-verdiana atende ao telefone e diz “Ó, brasilêro pa bosê̂” (Idem, 2009, p. 53). Observamos que existem marcas de oralidade no 50 texto para modificar a grafia das palavras "brasileiro", "para" e "você". Aqui temos uma marca da dicção da personagem, que pronuncia o português de forma diferente do narrador e das outras personagens, numa tentativa de imitar o sotaque do brasileiro. Constata-se também que essa imitação aparece contaminada pela pronúncia típica do norte de Portugal, que substitui o fonema [v], de "você", da norma padrão, pelo [b], "bocê""12. Apesar de se falar português em Cabo Verde, muitas pessoas não o usam como língua cotidianamente, mas outras línguas crioulas, o que deve ter levado o autor a marcar uma pronúncia caricatural da personagem. Essa mesma passagem foi traduzida por “Eh, le Brésilien, c'est pour toué” (Idem, 2015, p. 64), o que mostra que o tradutor modificou apenas um elemento da sentença, trocando o "toi" por "toué", imitando por transcrição fonética o sotaque proveniente de um meio social modesto localizado no norte da França, mas deixando o restante da frase em francês completamente compreensível e sem marca de estranhamento para o leitor francófono.

Outro momento em que temos a construção de uma "fonética artesanal" (BUCKEY, 2000) no romance é a pronúncia marcada no momento em que Serginho se comunica com os turistas em inglês: "Rei ser, rei mádam, Ria chípe fude, gude fude, uaine, fiche, mite, têm-quíu (Idem, 2009, p. 58), que foi traduzida pela representação dos sons em francês "Hé seur, Hé madame, Ire chipe foude, goude foude, ouaïne, fiche, mite, tainque-iou” (Idem, 2015, p. 71).

SALES; HEINEBERG. Representação de sotaques e oralidade na tradução francesa de Estive em Lisboa e lembrei de você, de Luiz Ruffato

Belas Infiéis, v. 7, n. 1, p. 39-58, 2018. 
Do mesmo modo, quando o narrador relembra das aulas de língua inglesa, aulas que agora o fazem valorizar a importante lição do "verbo tubî" $(2009$, p. 58) traduzido por "verbe toubi" (Idem, 2015, p.71). Ainda temos a frase "Didi iù enjóit it" (Idem, 2009, p. 58) que foi traduzida "Dide iou ainedjoeil ite" (Idem, 2015, p. 71). Aqui, Mathieu Dosse usou uma possível representação dos sons de língua inglesa em francês, da mesma forma como o autor brasileiro usou uma forma artesanal para representar a pronúncia do inglês. Esse tipo de transcrição revela a pouca familiaridade da personagem com o inglês e a necessidade de representar essa língua estrangeira passando pela língua materna.

Seis notas do tradutor inseridas no romance constituem paratraduções importantes da edição francesa. Três delas explicam referências relativas à cultura brasileira e afro-brasileira:

1. «A revolução de 1964 »é o nome popular (mas também empregado pelos defensores do regime militar) dado ao golpe de Estado que retirou o governo de João Goulart no dia primeiro de abril de 1964 e instaurou a ditadura militar no Brasil (nota do tradutor).

2. O “jogo do bicho", (“jeu de la bête” em francês) é um jogo de azar ilegal no Brasil. Muito popular, é um tipo de loteria na qual os números são trocados por animais (nota do tradutor.

3. O “jogo de búzios", “jeu de coquillages” em francês, é uma arte da adivinhação usada nas religiões afro-brasileiras ${ }^{13}$.

A primeira nota refere-se à ditadura militar, que é apresentada como "revolução de 1964”, termo geralmente utilizado pelos defensores do regime militar. Sua data é o dia primeiro de abril que, por coincidência, é também o dia da mentira no Brasil e, por isso, é importante entender o sentido cômico da passagem; "o Primeiro de Abril, dupla homenagem ao dia da Mentira e da Revolução de 1964 que, na opinião dos colegas mais políticos, dava no mesmo" (RUFFATO, 2009, p. 16). A segunda diz respeito ao "jogo do bicho", traduzido palavra por palavra em francês, "jeu de la bête", e explicitado como jogo de azar ilícito e muito comum no Brasil. Na nota, o tradutor faz um paralelo com a loteria, mas que troca os números pelos animais. A estratégia de traduzir palavra por palavra e depois explicar o seu sentido é semelhante para a tradução de "jogo de búzios", apresentado em francês na terceira nota como "jeu de coquillages", entendido como uma arte de adivinhação das religiões afro-brasileiras. Consideramos que tanto "revolução de 64", “jogo do bicho" e "jogo de búzios” fazem parte do repertório linguístico e cultural comum ao falante nativo. Portanto, seria desnecessário explicálos no texto de partida.

SALES; HEINEBERG. Representação de sotaques e oralidade na tradução francesa de Estive em Lisboa e lembrei de você, de Luiz Ruffato

Belas Infiéis, v. 7, n. 1, p. 39-58, 2018. 
Entretanto, as notas subsequentes apresentam elementos que seriam esclarecedores também para o leitor brasileiro:

\footnotetext{
4. « uma mão sozinha não aplaude » (nota do tradutor).

5. Os "retornados" são portugueses ou descendentes de imigrantes portugueses que voltaram, depois de morarem nas antigas colônias, para Portugal, particularmente após a revolução de 25 de abril de 1974. (nota do tradutor)

6. provérbio crioulo : «a diarreia não a atinge quem tem a bunda grande"14.
}

A quarta nota do tradutor corresponde a uma passagem na qual o cabo-verdiano Nino ri “na sua língua” e diz: "un son mon ka ta toka palmu” (RUFFATO ,2009, p. 58). Para o leitor brasileiro não há nenhuma tradução do sentido, nem nota explicativa, nem aposto para explicar o que a frase significa. Já a tradução apresenta uma nota do tradutor que faz a tradução do sentido na frase por um provérbio "une main seule n'applaudit pas" que, em português, seria “uma mão sozinha não aplaude", deixando o leitor francês ciente do sentido da frase, algo que não acontece no romance em português. A nota seis também corresponde a um provérbio crioulo apresentado no romance em português que não é explicado ao leitor "e o Nino, querendo me consolar, coitado, resmungou os dentes atristados, na língua lá dele "Panga bariga ka ta kontra ku bunda largu," (RUFFATO, 2009, p. 82). A tradução, diferentemente da edição brasileira, apresentada a frase inteira em negrito e coloca uma nota ao final do livro para explicar ao leitor do que se trata da frase: "et Nino, le pauvre, en voulant me consoler, a grommelé entre ses dents tristes, dans sa langue à lui, Panga bariga ka ta kontra ku bunda largu" (RUFFATO, 2015, p. 106). Na nota do tradutor, ele explica que a sentença é um provérbio crioulo e o traduz para o francês "La diarrhée n'atteint pas celui qui a de grosses fesses", "a diarréia não atinge quem tem bunda grande". Para o leitor brasileiro, a palavra "bunda" é entendida, pois a palavra existe no léxico do português do Brasil oriunda do "quimbundo mbunda, zona das nádegas"15, segundo o dicionário Priberam de língua Portuguesa.

Todavia, nem sempre a versão francesa traduz as palavras que causam estranhamento, deixando para o leitor o desafio de descobrir o que são e qual seu significado. Por exemplo, ao apresentar os menus encontrados nas ruas de Lisboa, Serginho usa um vocabulário que exige do leitor brasileiro um conhecimento da cultura africana para saber do que se trata: "apenas comia calulu, moamba de galinha com funge, munzugué com farinha de pau, muito óleo de palma e jindungo." (RUFFATO, 2009, p. 75). O texto em francês, dessa vez, foi traduzido como apresentado no texto em português sem explicações e sem acréscimos para ajudar o leitor:

$\overline{\text { SALES; HEINEBERG. Representação de sotaques e oralidade na tradução francesa de Estive em Lisboa e }}$ lembrei de você, de Luiz Ruffato 
"il ne mangeait que du calulu, de la moamba de poule avec du funge, du muzungué avec de la farine de manioc, beaucoup d'huile de palme et de jindungo" (RUFFATO, 2015, p. 95).

A nota número cinco diz respeito a uma palavra do contexto português, "retornados", que se refere aos "portugueses ou descendentes de portugueses que voltaram ao país depois de terem vivido nas ex-colônias" (Ibid., p.95). Esse acréscimo da tradução também ajuda o leitor a entender o contexto pós-colonial vivido pelos imigrantes das ex-colônias portuguesas, o que no texto brasileiro não fica evidente, pois a palavra é apresentada sem explicação, exigindo, mais uma vez, um conhecimento amplo por parte do leitor ou uma pesquisa sobre o vocábulo para entender seu sentido.

Trazendo para o leitor brasileiro elementos da realidade pós-colonial vivida por sua personagem Serginho em Lisboa, Ruffato revela ao leitor a cisão existente entre as culturas dos países de língua portuguesa. Se, por um lado, o autor brasileiro aponta para o passado comum que resulta na mobilidade contemporânea de homens e mulheres oriundos das antigas colônias - o retorno das caravelas ${ }^{16}$-, por outro, prefere acentuar, através das incompreensões linguísticas, por exemplo, as diferenças culturais e a impossibilidade de uma lusofonia ${ }^{17}$, sobretudo para o Brasil, que passou pelo processo de descolonização muito antes das colônias africanas.

\section{Considerações finais}

Como vimos, o romance Estive em Lisboa e lembrei de você constrói uma narrativa que acolhe diversas vozes marcadas por uma pluralidade de construções orais e de expressões de variantes da língua portuguesa. Além de emprestarem ao texto uma representação verossimilhante do falar brasileiro, as marcas de oralidade são uma das estratégias literárias empregadas por Ruffato para deixar evidentes as diferenças linguísticas e culturais entre Portugal e suas ex-colônias. Muitas vezes essas falas marcadas pela oralidade evidenciam também conflitos internos na narrativa, desentendimentos linguísticos que se constituem quase como uma metáfora dos desentendimentos e conflitos entre as nações de língua oficial portuguesa. Reunidos em Lisboa, migrantes econômicos oriundos de diversos países outrora colonizados por Portugal revelam, através de seus falares, a dominação cultural e linguística, suas consequências e, finalmente, os reflexos econômicos do processo colonial nas sociedades atuais. Apesar de possuírem uma língua em comum, os diferentes registros que constroem as personagens marcam contextos sociais distintos. Apesar de existir a compreensão da língua, muitas vezes existem ruídos nessa comunicação.

SALES; HEINEBERG. Representação de sotaques e oralidade na tradução francesa de Estive em Lisboa e lembrei de você, de Luiz Ruffato

Belas Infiéis, v. 7, n. 1, p. 39-58, 2018. 
Na tradução de Mathieu Dosse, o texto teve como proposta desenvolver diversos níveis de registro na fala das personagens, mantendo, quando possível, algumas palavras do texto de partida. Dessa forma, vimos que o tradutor apresenta palavras da variante europeia que causam estranhamento para o leitor brasileiro, logo em seguida traduzindo-as para o francês dentro da narrativa. Outra importante ampliação do texto que a tradução apresenta é a utilização de notas explicativas de palavras e de contextos culturais específicos do Brasil. Vimos também que a tradução francesa opta por oferecer uma tradução cultural de palavras originárias do contexto português e africano de língua portuguesa. Ao passo que Ruffato nega a existência e a possibilidade de uma "lusofonia", a tradução, quando aposta na tradução cultural, torna menos evidente esse estranhamento.

Desse modo, passagens que podem parecer obscuras ao leitor brasileiro que não tem conhecimentos aprofundados sobre o contexto africano lusófono ou português tornam-se acessíveis na tradução ao público francês. Entendemos que o texto original de Ruffato sugere, através desse estranhamento linguístico, o estranhamento pós-colonial entre os países reconhecidos como "lusófonos" apenas pelos portugueses.

\section{REFERÊNCIAS BIBLIOGRÁFICAS}

AUGÉ, Marc. Non-lieux. Introduction à une anthropologie de la surmodernité, Paris : Seuil, 1992.

ANTUNES, Lobo. As Naus. Lisboa: Dom Quixote, 2010 (1988).

BERMAN, Antoine. A prova do estrangeiro. Tradução de Maria Emília Pereira Chanut. São Paulo: EDUSC, 2002.

BERMAN, Antoine. A Tradução e a Letra ou o Albergue do Longínquo. Tradução de MarieHélène C. Torres, Mauri Furlan, Andreia Guerini. Santa Catarina: 2a . Edição. Copiart UFSC, 2012.

BRITTO, Paulo Henriques. A tradução literária. Rio de Janeiro: Edições Civilização Brasileira, 2012.

BUCKLEY, Thomas. Oralité, distance sociale et universalité. In: BALLARD, Michel. Oralité et Traduction. Arras : Artois Presse Universitaire, 2000.

FONSECA, Ana Margarida, "Em português nos entendemos? Lusofonia, literatura-mundo e as derivas da escrita", Configurações, 12/2013. Disponível em: <http://configuracoes.revues.org/2041>. Acesso 17/11/2017.

GENETTE, Gérard. Seuils. Paris: Éditions du Seuil, 2002.

SALES; HEINEBERG. Representação de sotaques e oralidade na tradução francesa de Estive em Lisboa e lembrei de você, de Luiz Ruffato

Belas Infiéis, v. 7, n. 1, p. 39-58, 2018. 
GUERINI, Andreia; AIRES, Leomaris. Tradutores de Luiz Ruffato em francês, italiano e alemão. In: Cadernos de Tradução. Florianópolis, v. 37, $\mathrm{n}^{\circ} 3$, p. 406-425, set-dez 2017.LEJEUNE, Philippe. Le Pacte autobiographique. Seuil, coll. "Poétique", 1975.

LE PETIT ROBERT DE LA LANGUE FRANÇAISE, Paris: Édition Le Robert, 2017.

MARTINS, Elisa. Entrevista Luiz Ruffato fala sobre os impasses das traduções de romances. O Globo. Cidade do México, Cultura, Prosa, 2012. Disponível em: <http://blogs.oglobo.globo.com/prosa/post/luiz-ruffato-fala-sobre-os-impasses-das-traducoesde-romances-476252.html>. Acesso em: 10/08/2017

MORTAIGNE, Véronica. L'exil, avec ou sans tabac. In: Le monde. Disponível em: <http://www.lemonde.fr/livres/article/2015/03/18/l-exil-avec-ou-sans-

tabac_4596332_3260.html>. Acesso em: 20/08/2017

PAGANINE, Carolina; FONSECA, Ester. Algumas considerações sobre variação linguística e tradução literária In: Revista Non Plus, nº 7, Universidade de São Paulo, 2015. Disponível em: <https://www.revistas.usp.br/nonplus/article/view/106913>. Acesso em: 15/05/2017.

PRETI, Dino. Análise de textos orais. Projetos Paralelos-NURC/SP (Núcleo USP), vol. 1, São Paulo: Humanitas, 1999.

ROSA, Gian Luigi. Problemáticas tradutórias e adequação sociolinguística: a tradução italiana de Estive em Lisboa e lembrei de você de Luiz Ruffato. De volta ao futuro da língua portuguesa, Atas do V Simpósio Mundial de Estudos de Língua Portuguesa, Simpósio 28 Desafios e estratégias tradutórias para o século XXI e a tradução aplicada ao ensino de PLE, p. 3695-3706. Disponível em: <http://sibaese.unisalento.it/index.php/dvaf/article/download/18099/15440>. Acesso em: 17/11/17.

RUFFATO, Luiz. Eles eram muitos cavalos. Editora Boitempo Editorial, 2001.

RUFFATO, Luiz. Come tanti cavalli. Tradução Patrizia di Malta. Milão: Bevivino Editore, 2003.

RUFFATO, Luiz. Eles eram muitos cavalos. Espinho: Quadrante Edições, 2006.

RUFFATO, Luiz. Tant et tant de chevaux. Tradução de Jacques Thiériot. Éditions Métaillé, 2005.

RUFFATO, Luiz. Des gens heureux. Tradução Jacques Thiériot. Paris: Éditions Métailié, 2007.

RUFFATO, Luiz. Rutosti hevosia. Tradução Jyrki Lappi-Seppälä. Helsinki: Into, 2014.

RUFFATO, Luiz. Estive em Lisboa e lembrei de você. Companhia das Letras: São Paulo, 2009.

RUFFATO, Luiz. Estive em Lisboa e lembrei-me de ti. Lsiboa: Editora Quetzal, 2010.

SALES; HEINEBERG. Representação de sotaques e oralidade na tradução francesa de Estive em Lisboa e lembrei de você, de Luiz Ruffato

Belas Infiéis, v. 7, n. 1, p. 39-58, 2018. 
RUFFATO, Luiz. Le monde ennemi. Tradução Jacques Thiériot. Paris: Éditions Métailié, 2010.

RUFFATO, Luiz. Ellos eran muchos caballos. Tradução Mario Camara. Buenos Aires: Eterna Cadencia, 2010.

RUFFATO, Luiz. Sono stato a Lisbona e ho pensato a te. Tradução Gian Luigi de Rosa. Roma: La Nuova Frontiera: 2011.

RUFFATO, Luiz. Estuve en Lisboa y me acordé de ti. Tradução Mario Camara. Buenos Aires: Eterna Cadencia, 2011.

RUFFATO, Luiz. Mamma, son tanto Felice. Tradução Maria Cristina Hernández Escobar. Cidade do México: Elephas, 2011.

RUFFATO, Luiz. EI mundo enemigo. Tradução Maria Cristina Hernández Escobar. Cidade do México: Elephas, 2012.

RUFFATO, Luiz. Ellos eran muchos caballos. Tradução Mario Camara. Bogotá: Rey + Naranjo, 2012.

RUFFATO, Luiz. Es waren viele Pferde. Tradução Michael Kegler. Berlim: Assoziation A, 562012.

RUFFATO, Luiz. "Quero fazer da literatura algo que modifique o leitor", entrevista concedida a Cláudia Aranda, Ponto final, 10/3/2016. Disponível em: https://pontofinalmacau.wordpress.com/2016/03/10/luiz-ruffato-quero-fazer-da-literaturaalgo-que-modifique-o-leitor/. Acesso 17/11/17.

ROSA, Victor. Luiz Ruffato e Michael Kleger: prêmio literário internacional Hermann Hesse. Goethe Institut. Cultura, 2016. Disponível em: <https://www.goethe.de/ins/br/pt/kul/mag/20806181.html>. Acesso em: 24/08/2017.

SILVA, Rosa Virgínia Mattos e. O Português Arcaico. Uma Aproximação, vol. II, Lisboa, Imprensa Nacional/Casa da Moeda, 2008.

SCHØLLHAMMER, Karl Erik. Ficção brasileira contemporânea. Rio de Janeiro: Civilização Brasileira, 2009.

TACCA, Oscar. Las voces de la novela. $3^{\text {a }}$ edição. Madrid: Gredos, 1973.

TORRES, Marie-Helène Catherine. Traduzir o Brasil Literário: Paratexto e discurso de acompanhamento. Vol. 1. Tubarão: Copiart, 2011.

VITALI, Ilaria (Org.). Intrangers (II) Littérature beur, de l'écriture à la traduction. Louvain-la-neuve: L'harmattan, 2011.

$\overline{\text { SALES; HEINEBERG. Representação de sotaques e oralidade na tradução francesa de Estive em Lisboa e }}$ lembrei de você, de Luiz Ruffato

Belas Infiéis, v. 7, n. 1, p. 39-58, 2018. 
YUSTE FRÍAS, J. Au seuil de la traduction : la paratraduction. In : NAAIJKENS, T. [ed./éd.]. Event or Incident. Événement ou Incident. On the Role of Translation in the Dynamics of Cultural Exchange. Du rôle des traductions dans les processus d'échanges culturels. col./coll. Genèses de Textes-Textgenesen (Françoise Lartillot [dir.]), vol. 3. Bern, Berlin, Bruxelles, Frankfurt am Main, New York, Oxford, Wien: Peter Lang, 2010. pp. 287-316.

\footnotetext{
${ }^{1}$ Kall Lyws Barroso SALES - Doutor (2018) e Mestre (2014) em Estudos da Tradução pela Universidade Federal de Santa Catarina. Graduado em Letras Português-Francês (2009) pela Universidade Federal do Ceará. Graduado em Gestão de Sistemas Produtivos (2007) pela Faculdade de Tecnologia do Nordeste. Florianópolis, Santa Catarina, Brasil. Lattes: http://lattes.cnpq.br/6834884715432315 E-mail: kalllyws@ gmail.com
}

2 Ilana HEINEBERG - Doutora em Études Lusophones (2004) e Mestre em Letras (2000) ambos pela Université de Paris III (Sorbonne-Nouvelle). Graduada em Jornalismo (1996) pela Pontifícia Universidade Católica do Rio Grande do Sul. Maître de conférences na Université Michel de Montaigne-Bordeaux 3. Bordeaux, França. Lattes: http://lattes.cnpq.br/5589195766147216 E-mail: iheineberg@yahoo.com

${ }^{3}$ Em 2000, o autor recebeu uma menção especial em Havana pela publicação no mesmo ano do livro de contos $O s$ sobreviventes. Seu primeiro romance, Eles eram muitos cavalos, publicado em 2001, se apresenta de forma diferente dos seus livros de contos anteriores, que tinham uma narrativa voltada a moradores e trabalhadores de Cataguases, cidade em que nasceu. Entretanto, em seu primeiro romance, temos apresentadas as vivências e experiências do dia-a-dia dos moradores de São Paulo, pessoas simples, que andam de metrô em metrô, que passam por nós todos os dias e de quem não sabemos sequer o nome. Essa realidade da metrópole seca e sem vida está apresentada na forma rápida e concisa das descrições de Ruffato (2001, p. 94). Apresentar seu primeiro romance é essencial, pois esta obra foi muito bem recebida pela crítica por sua inovação e forma narrativa. Em 2001, ano de seu lançamento, recebeu o prêmio Machado de Assis da Fundação Biblioteca Nacional. Neste romance, Ruffato evidencia que sua escrita em prosa apresenta diversos elementos da poesia, do teatro, da oralidade, o que deixa o leitor "sem saber se leu poesia, prosa, prosa poética ou todas ao mesmo tempo", como afirma Fanny Abramovich ao apresentar a edição brasileira (RUFFATO, 2001).

${ }^{4} \mathrm{O}$ tradutor, que também é professor de literaturas de língua portuguesa, escreveu um artigo a respeito das problemáticas tradutórias e da adequação sociolinguística da tradução (Cf. ROSA, 2017).

${ }^{5}$ Em entrevista concedida a Elisa Martins, do jornal $O$ Globo, Ruffato faz uma reflexão sobre a tradução dos seus textos no mercado editorial latino-americano, bem como apresenta uma íntima relação entre tradução, literatura e economia. $\mathrm{O}$ autor ainda reflete sobre os entraves que afastam as literaturas brasileira e mexicana e apresenta a necessidade de criação de um instituto de ensino do português do Brasil, semelhante ao Instituto Camões de Portugal.

${ }^{6}$ É possível encontrarmos em algumas traduções francesas a apresentação do português brasileiro apenas como "brasileiro", fazendo a distinção da língua falada no Brasil, o brasileiro, e a língua falada em Portugal, o português.

${ }^{7}$ Utilizamos o termo tradução assumida segundo a obra de TORRES (2011), que vai diferenciar as traduções que são assumidas na capa, na segunda capa, no expediente do livro daquelas que não fazem menção ao processo tradutório.

8 Disponível em: <http://www.lemonde.fr/livres/article/2010/05/20/luiz-ruffato-l-impossibilitedurecit_1360624_3260.html>. Acesso: 24/08/2017.

${ }^{9}$ O projeto Amores Expressos teve a participação de dezessete escritores que foram levados para dezessete cidades ao redor do mundo. Os escritores tinham como compromisso escrever um romance em seu retorno que seria editado pela editora Companhia das Letras.

SALES; HEINEBERG. Representação de sotaques e oralidade na tradução francesa de Estive em Lisboa e lembrei de você, de Luiz Ruffato

Belas Infiéis, v. 7, n. 1, p. 39-58, 2018. 
${ }^{10}$ Aqui utilizamos o conceito de Yuste Frías defendido no texto Au seuil de la traduction: la paratraduction, de 2010, em que o teórico afirma que os elementos paratextuais presentes apenas no texto traduzido, como as notas do tradutor, as imagens da capa, a apresentação do autor, e outras explicações configuram o que ele entende por paratradução.

${ }^{11}$ Serginho, le narrateur, est un Brésilien de Minas Gerais. Dans la seconde moitié du récit, sa langue brésilienne, riche en expressions familières, va peu à peu intégrer le vocabulaire lisboète. Ces nouveaux mots et expressions sont soulignés, ici et dans l'édition originale, en gras. Comment traduire ce changement subtil ? Nous avons choisi de laisser, lorsque cela nous paraissait la meilleure solution, le mot en portugais suivi d'une traduction. D'autre fois, il nous a paru nécessaire de traduire cet effet d'étrangeté, de depaysement, que produit souvent le «portugais de Portugal » aux oreilles d'un Brésilien. Ainsi, nous avons traduit certains mots ou expressions portugaises par des archaïsmes («gouailler »), des mots inhabituels en français, un peu vieillots (« girie», « lieux d'aisance »), ou des régionalismes («cellulaire»). Enfin, plus rarement, nous avons traduit, lorsqu'elle prêtait à sourire, l'expression à la lettre (« chapeau à pluie » pour « parapluie »). On parle, bien entendu, au Portugal et au Brésil, la même langue, mais les différences sont assez fortes pour que Serginho puisse s'exclamer, lorsqu'il fait la connaissance d'un compatriote à Lisbonne : «Quand même, ça fait du bien de rencontrer quelqu'un qui parle la même langue que vous ».

${ }^{12}$ Sobre o arcaísmo dessa variante dialetal do norte de Portugal, cf. Silva, 2008, p. 549.

13 1. «La Révolution de 1964 » est Le nom populaire (mais aussi celui employé par les défenseurs du régime militaire) donné au coup d'État qui renversa le gouvernement de João Goulart le $1^{\text {er }}$ Avril 1964 et instaura la dictature militaire au Brésil. (note du traducteur)

2. Le « jogo do bicho », (« jeu de la bête », en français) est un jeu au hasard illégal au Brésil. Très populaire, il ressemble à une lotterie dans laquelle les chiffres sont remplacés par des animaux. (ndt)

3. Le « jogo de búzios », jeu de coquillages, est un art divinatoire utilisé dans les religions afro-brésiliennes.

14 4. « une main seule n'appladit pas. » (ndt)

5. Les « retornados » sont des Portugais ou des descendants d'immigrés portugais qui sont revenus, après avoir habité les anciennes colonies, au Portugal, en particulier après la révolution du 25 avril 1974. (ndt)

6. Proverbe créole : «La diarrhée n’atteint pas celui qui a de grosses fesses. » (ndt.)

$15<$ https://www.priberam.pt/dlpo/bunda> . Acesso em: 20/08/2017.

${ }^{16}$ Esse regresso dos colonos contraposto aos grandes mitos das grandes descobertas constitui o fio condutor do romance As Naus (1988), do escritor português Lobo Antunes, que inicialmente deveria intitular-se $O$ regresso das caravelas.

${ }^{17}$ De fato, Rufatto tem uma visão bastante crítica da "lusofonia". Para o escritor, não há uma cultura comum a todos os países de língua portuguesa: “É um problema sério você pensar no conceito de lusofonia. O que é lusofonia? Eu não sei o que é. Serão os países de cultura portuguesa? O Brasil não é um país de cultura portuguesa. Vai perguntar a um brasileiro descendente de japonês se é de cultura portuguesa ou a um descendente de alemão ou de italiano, como eu sou? Nós não somos descendentes da cultura portuguesa, nós falamos português." (RUFFATO, 2016). Sobre o conceito de lusofonia num contexto pós-colonial, consultar FONSECA, 2013.

SALES; HEINEBERG. Representação de sotaques e oralidade na tradução francesa de Estive em Lisboa e lembrei de você, de Luiz Ruffato

Belas Infiéis, v. 7, n. 1, p. 39-58, 2018. 